\title{
Ultrasound and gross anatomy of the brachial plexus and major nerves of the forelimb. An anesthetic approach using the domestic rabbit (Oyctolagus cuniculus) as an experimental model ${ }^{1}$
}

\author{
Rodrigo Mencalha ${ }^{\text {I }}$, Carlos Augusto dos Santos Sousa ${ }^{\text {II }}$, Orlando Costa ${ }^{\text {III }}$, Marcelo Abidu-Figueiredo ${ }^{\text {IV }}$ \\ DOI: http://dx.doi.org/10.1590/S0102-865020160040000001 \\ ${ }^{I} \mathrm{MSc}$, Associate Professor, Department of Veterinary Surgery and Anesthesiology, School of Veterinary Medicine, Centro de Ensino Superior de \\ Valença (CESVA), Valença-RJ, Brazil. Fellow PhD degree, Postgraduate Program in Veterinary Medicine, Universidade Federal Rural do Rio de \\ Janeiro (UFRRJ), Seropédica-RJ, Brazil Intellectual and scientific content of the study, ultrasonographic exams, statistical analysis, manuscript writing, \\ critical revision.

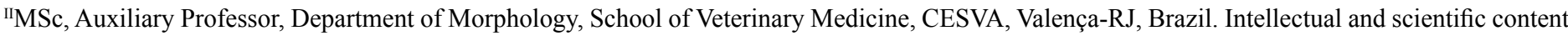 \\ of the study, anatomic dissections, statistical analysis, manuscript writing, critical revision. \\ IIIMSc, Assistant Professor, Department of Animal Biology, School of Veterinary Medicine, UFRRJ, Seropédica-RJ, Brazil. Intellectual and scientific \\ content of the study, statistical analysis, critical revision. \\ ${ }^{\text {IV }} \mathrm{PhD}$, Associate Professor, Department of Animal Biology, School of Veterinary Medicine, Postgraduate Program in Veterinary Medicine, UFRRJ, \\ Seropédica-RJ, Brazil. Intellectual and scientific content of the study, statistical analysis, critical revision.
}

\begin{abstract}
PURPOSE: To update the gross and sonographic anatomy and propose landmarks to perform ultrasound-guided (US-guided) axillary brachial plexus block (BPB) in rabbits.

METHODS: Forty New Zeeland's rabbit (NZR) cadavers were dissected and the nerves were trimmed, identified, measured, and photographed. Additionally, in twenty NZRs, sonographic images of brachial plexus (BP) were performed through a simple-resolution ultrasound device. The US-guided block was achieved through a minimum volume of lidocaine necessary to surround the BP roots. The effectiveness of the brachial plexus block was assessed on sensitivity and motor functions.

RESULTS: The BP resulted from connections between the ventral branches of the last four cervical spinal nerves and the first thoracic spinal nerve. In the axillary sonoanatomy, the BP appeared as an agglomerate of small, round hypoechoic structures surrounded by a thin hyperechoic ring. The amount of time and the minimum volume required to perform was $4.3 \pm 2.3 \mathrm{~min}$ and $0.8 \pm 0.3 \mathrm{ml}$, respectively.

CONCLUSIONS: The gross and sonographic anatomy of the BP showed uncommon morphological variations. Moreover, from sonographic landmarks, we showed complete reproducibility of the axillary US-guided brachial plexus block with simple resolution equipment and small volume of anesthetics required.

Key words: Anatomy. Brachial Plexus. Anesthesia, Conduction. Ultrasonography. Rabbits.
\end{abstract}




\section{Introduction}

Surgical orthopedic and oncologic procedures in the forelimb are routinely performed in humans and small animals, triggering neuroendocrine responses and severe postoperative pain. Therefore, multimodal analgesia schemes are essential for the appropriate management of prevalent and often-neglected ilnesses ${ }^{1}$. The association of parenteral analgesic drugs with locoregional anesthesia can be considered a promising tool to abolish noxious stimuli provoked by surgery. Locoregional anesthesia and peripheral nerve blocks are widely used in human anesthesia, and the use and evaluation of this technique have also been described in small and laboratory animals.

The study of anatomical landmarks, morphology and morphometric are important to optimize the results of surgical and anesthetic interventions ${ }^{2,3}$. Until the last century, locoregional blocks were exclusively performed through anatomical references, and consequently had high rates of failure and injury. However, currently high-resolution electronic ultrasound (US) transducers have been increasingly used for human regional anesthesia, allowing visualization of the neural and adjacent structures as well the dispersion of local anesthetic in real time. Sonographic visualization enables optimal distribution of local anesthetics around the nerve structures and the avoidance of complicated procedures such as intraneural and intravascular injection.

Visualization of the BP using ultrasonography has been previously described in humans ${ }^{4}, \operatorname{dogs}^{5}$, and cats ${ }^{2}$. To improve the results of locorregional anesthesia, animal models can be very useful investigative tools ${ }^{6}$. In the choice of the experimental model, besides the possibility of carrying out anesthetic procedures on the nerve branches, the basic criterion is the ability to objectively evaluate the results.

We believe that the rabbit can be an experimental model for studies related to the $\mathrm{BP}$, since the anatomical structure of rabbits' brachial plexus is similar to that in other domesticated animals $^{5}$ as well as humans ${ }^{6}$. Furthermore, they have adequate size, are docile and easy to handle.

Our laboratory research involves an experimental model of locoregional anesthesia and presents morphology, morphometry and sonoanatomy of the rabbit brachial plexus and its application in locoregional anesthesia. This study aimed to update the gross anatomy and sonographic anatomy of the domestic rabbit and propose anatomical landmarks to perform axillary ultrasoundguided brachial plexus block

\section{Methods}

This work includes partial results of the project entitled "Morphological, Electromyographic and Infrared Thermography of Ultrasound Guided Brachial Plexus Block", which was approved by the research ethics committee of the Biological and Health Sciences Institute of Universidade Federal Rural do Rio de Janeiro (UFFRJ), under protocol 006/2014. The aim of the project is to establish complete understanding of the topographical and sonographic anatomy of the region for performing blocks of the forelimb.

The research was divided into two phases: anatomic and ultrasonographic. The anatomic study was conducted in 40 New Zeeland rabbit cadavers (20 males and 20 females), with a mean weight of $2.4 \mathrm{~kg}$ (range 1.8 to $3.1 \mathrm{~kg}$ ). These rabbits were previously sexed and fixed in formaldehyde solution in the Laboratory of UFFRJ. In the ultrasonographic study, 20 adult New Zeeland rabbits, 10-12 weeks old, four males and four females, with mean weight of $2.5 \mathrm{~kg}$ (range $2.1-3.4 \mathrm{~kg}$ ) were used. The rabbits utilized in the ultrasonographic study were obtained from the Zootechny Department of UFRRJ. Only healthy animals were selected for this experimental test, which had been rigorously examined and certified as healthy through laboratory tests. The animals were housed under controlled environmental conditions, with a room temperature $20-21^{\circ} \mathrm{C}$, relative humidity of $50-55 \%$ and 10 fresh air changes per hour. Photoperiod consisted of $12 \mathrm{~h} /$ $12 \mathrm{~h}$ light / dark cycle.

\section{Anatomical study}

In 20 fixed male and 20 female rabbits, the skin was reflected from the elbow to the sternum do expose the muscles. The overlying fascia was removed and the pectorals superficial and profundus muscles were exposed. Furthermore, the scapula and humerus were abducted to expose the nerves and blood vessels located at the axillary region. Connective and fat tissue were removed and the nerves were trimmed, identified, measured and photographed (Nikon D3200). The same operator, with an electronic caliper rule, performed the measurements.

Furthermore, to identify the ventral rami of cervical and thoracic spinal nerves participating in the formation of the brachial plexus, we recorded the data in schematic drawings. The data were organized in tables for the establishment of frequency in relation to the type of occurrence. 


\section{Ultrasonographic study}

In twenty rabbits, ultrasonographic examinations of the brachial plexus were performed through a simple-resolution ultrasound device (Mindray P/B - DP 2200 VET). After sedating the animals with $10 \mathrm{mg} / \mathrm{kg}$ of ketamine (Agener União, São Paulo, Brazil) and $1.0 \mathrm{mg} / \mathrm{kg}$ of midazolam (Dormire, Cristália, São Paulo Brazil), they were positioned in lateral recumbence with the contralateral thoracic limb was abducted. The skin was cleaned and acoustic coupling gel applied. A 7.5 -10 MHz - $5 \mathrm{~mm}$ linear electronic transducer was used.

As previously described ${ }^{7}$, the brachial plexus was scanned from the origin at the level of the intervertebral foramina to the branches of the axillary, musculocutaneus, radial, ulnar and median nerves at the elbow. This region was shared in axillar and humeral zones in order to unify the examinations. The humeral zone was divided into four regions: proximal (from the shoulder to the proximal diaphysis); median (mid-diaphysis area); distal (from the distal diaphysis to the elbow); and lateral (in distal humerus). The nerves were scanned only in transverse plane. The orientation marker of the transducer was oriented cranially. The landmarks to approach the axillar region included the scapula-humeral joint and lateral aspect of the first rib. The transducer was positioned in the space between the shoulder joint and the sternum, aligned parallel to the vertebral column and the ultrasound bar was directed in the craniodorsal direction.

The humeral zone was approached from the scapulahumeral joint to the elbow. The transducer was positioned at the medial aspect of the proximal humerus to approach the proximal part of the medial region. The probe was placed in a transverse plane relative to the humerus and the nerves were identified. Small adjustments were made to the transducer orientation to produce the best suitable transverse images of the nerves. Then the transducer was positioned at the axillar aspect of the midhumerus to approach the medial part of the humerus, following the same steps described for the proximal part of the humerus zone. The distal humeral approach was divided into two aspects: medial and lateral. The transducer was positioned transverse to the medial aspect of the distal humerus and then at the lateral aspect. The humeral lateral zone was approached from the humerus to the lateral head of the triceps brachi muscle.

For each approach, the appearance, echogenicity and echotexture of components of the brachial plexus, major nerves, and surrounding structures were recorded.

\section{Ultrasound-guided brachial plexus block}

Through a simple-resolution ultrasound device and a nerve stimulator (Stimuplex HNS 12; Bbraun; Melsugen AG, Melsugen, Germany) we performed the axillary brachial plexus block similarly with a recently technique described in rabbits ${ }^{8}$. With the thoracic plane in which we planned to carry out the nerve block placed uppermost and in abduction. After thorough clipping of the fur, the axillary area was prepared aseptically by topical application of alcoholic chlorhexidine. The transducer was placed in the axilla, allowing visualization of the axillary artery and vein and hyperchoic structures just dorsal to the vessels identified as the brachial plexus. Once the target nerves were centered in the visual field, the nerve stimulator needle (Stimuplex A50 22Gx2") was inserted longitudinally toward the nerve while continuing sense to maintain the motor response. Adjustments to the current strength led to reductions of the third impulse. At the threshold of $0.3 \mathrm{~mA}$, three thoracic limb twitches were visible as all three impulses elicited a motor response, confirming proximity of the needle tip to the nerve. At this point we used the minimum volume of $2.0 \%$ lidocaine necessary to surround the branches of $\mathrm{C} 5, \mathrm{C} 6$, $\mathrm{C} 7, \mathrm{C} 8$ and $\mathrm{T} 1$ with a pre-established maximum dose of $1.0 \mathrm{ml}$ per $\mathrm{Kg}$ body weight.

\section{Nerve block assessment}

The effectiveness of the brachial plexus block was assessed through sensitivity and motor function. The sensitivity function was evaluated by applying a noxious stimulus (pinching) using a Halstead mosquito straight hemostatic forceps. This involved clamping the skin between each digit and in the cranial and lateral portions of the radius and humerus. All impingements proposed was performed for a period of ten seconds each, with the pressure exerted to reach the first tooth of the rack. To avoid tearing the skin by the pinching, a plastic segment was used to cover the jagged region of tweezers. The painful response to impingement was confirmed by the attitude of the animal using the following criteria: head wiggling, vocalization, attempt to bite, movements of other body parts, and protective reflexes like member bending 9 . The motor function was evaluated by testing the limb's ability to bear weight.

The data obtained in this study were registered through photographs. The modalities were grouped into tables to perform the statistical analysis, which in this case was only computing frequency percentage. 


\section{Results}

\section{Anatomic study}

The male rabbits dissected had a mean length of $42.80 \pm$ $2.827 \mathrm{~cm}$ and the females $41.93 \pm 5,165 \mathrm{~cm}$. The plexuses appeared as wide and thin tracks that reached the axillary space through the muscles of the neck and ventral scalene, which concealed output of the cervical nerves through the intervertebral foramina. In these animals, 90\% resulted from connections established mainly between the ventral branches of the last four cervical spinal nerves (C5, C6, C7 and C8) and the first thoracic spinal nerve (T1) (Figure 1).

In rabbits, the ventral branch of $\mathrm{C} 4$ is primarily for innervation of neck muscles issuing a trunk to the more superficial muscles of this region and also contributes to the origin of the phrenic nerve. We found that the ventral branch of $\mathrm{C} 5$ also participated in the formation of the phrenic nerve and in some cases issued a trunk for the superficial cervical muscles and still connected with the trunk formed from $\mathrm{C} 4$.

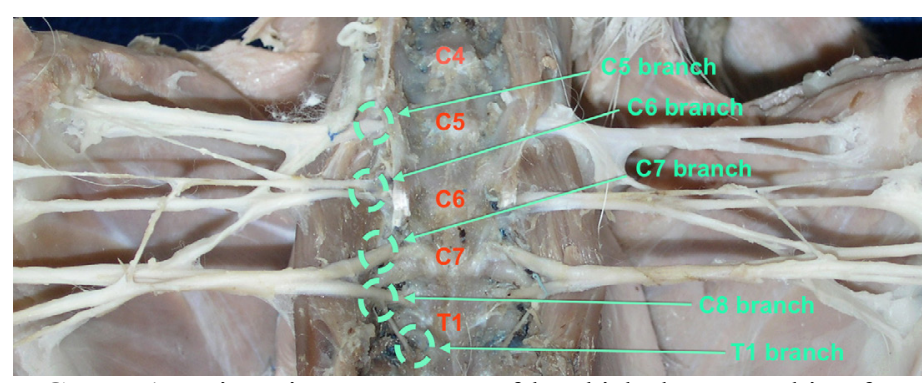

FIGURE 1 - Dissection appearance of brachial plexus resulting from connections established mainly between the ventral branches of the last four cervical spinal nerves $(\mathbf{C 5}, \mathbf{C 6}, \mathbf{C} 7$ and $\mathbf{C 8})$ and the first thoracic spinal nerve (T1)

In 80 plexuses in which C5 participated, this occurred through a thin connection with $\mathrm{C} 6$. The ventral rami of the sixth, seventh and eighth cervical nerves and the first thoracic spinal nerve always participate in the formation of the brachial plexus. Another important factor is that the $\mathrm{C} 6$ branch provided the contribution flow to form the root of the phrenic nerve.

The involvement of the ventral ramus of the second thoracic spinal nerve was observed in $7.5 \%$ of the dissected animals, and its participation occurred through a T1 connection, but most of $\mathrm{T} 2$ formed the second intercostal nerve, which crossed the internal and external intercostal muscles. The occurrence of the $\mathrm{T} 2$ contribution to the brachial plexus was always symmetric, i.e., it occurred in both antimeres.
According to the combination of the ventral branches of $\mathrm{C} 4, \mathrm{C} 5, \mathrm{C} 6, \mathrm{C} 7, \mathrm{C} 8, \mathrm{~T} 1$ and $\mathrm{T} 2$ as roots of brachial plexus, three types were obtained with different origins. Each of them is described in Table 1, along with the frequency.

TABLE 1 - Types of brachial plexus found in rabbits (males and females).

\begin{tabular}{cccc}
\hline Type & Ventral Branches & $\begin{array}{c}\text { Absolut } \\
\text { Frequency }\end{array}$ & $\begin{array}{c}\text { Simple } \\
\text { Percentage } \\
\text { Frequency }\end{array}$ \\
\hline I & C5, C6, C7, C8, T1 & 74 & 92.5 \\
II & C5, C6, C7, C8, T1, T2 & 4 & 2.5 \\
III & C4, C5, C6, C7, C8, T1, T2 & 2 & 5.0 \\
Total & & 80 & 100 \\
\hline
\end{tabular}

\section{Description and morphometry of brachial plexus nerves}

The components of the brachial plexus were identified from cranial to caudal as follows: suprascapular nerve, subscapular nerve, axillary nerve, musculocutaneus nerve, radial nerve and the common trunk of the median and ulnar nerve (Figure 2). The nerves were located within the connective tissue of the axillary space.

1. Suprascapular nerve: derived from the ventral rami of the fifth cervical components (C5) $(90.00 \%)$ and in some cases received contribution of the sixth cervical nerve (C6) $(9.75 \%)$ and fourth cervical nerve (C4) (1.25\%). In males, the average length in right antimere was $2.984 \pm 0.6697 \mathrm{~cm}$ and in left antimere was $3.108 \pm 0.6285 \mathrm{~cm}$. In females, the average length in right antimere was $2.822 \pm 0.4884 \mathrm{~cm}$ and in left antimere was $2.950 \pm$ $0.5004 \mathrm{~cm}$.

2. Subscapular nerve: originated from the ventral rami of the sixth and seventh cervical nerves (C5 and C6) (100.00\%). In males, the average length in right antimere was $2.924 \pm 0.6371$ $\mathrm{cm}$ and in left antimere was $3.089 \pm 0.6543 \mathrm{~cm}$. In females, the average length in right antimere was $2.948 \pm 0.4602 \mathrm{~cm}$ and left antimere was $3.041 \pm 0.4257 \mathrm{~cm}$

3. Axillary nerve: formed from fibers of the sixth and seventh cervical nerves (C6 and C7) $(100.00 \%)$. In males, the average length in right antimere was $3.844 \pm 0.8097 \mathrm{~cm}$ and in left antimere was $3.901 \pm 0.8257 \mathrm{~cm}$. In females, the average length in right antimere was $3.680 \pm 0.5528 \mathrm{~cm}$ and left antimere was 3.711 $\pm 0.5752 \mathrm{~cm}$. 
4. Musculocutaneus nerve: in $90 \%$ of cases was formed by fibers from branches of the seventh and eighth cervical nerves (C7, C8) and $10 \%$ there was contribution of the first thoracic nerve (T1). This nerve passed cranially to the brachial artery and detached a communicating branch to the median nerve. Furthermore, it descended along the medial surface of the biceps brachii muscle. In males, the average length in right antimere was $4.396 \pm 0.7172$ and in the left antimere was $4.509 \pm 0.8280$. In females, the average length in right antimere was $4.023 \pm 0.4797$ $\mathrm{cm}$ and left antimere was $4.033 \pm 0.6013 \mathrm{~cm}$.

5 . Radial nerve: resulted primarily from ventral branches of C8 and T1 (92.5\%), although some cases there only was participation of the ventral branches of T2 (7.5\%). This nerve was visualized as a single nerve in the axillary region and was divided into a cluster of multiple fibril components distal to the scapulohumeral joint. Furthermore, it descended between the axillaris nerve and the common trunk of the median and ulnar nerves, immediately cranial to the axillaris artery and vein. The radial nerve continued distally between the subscapular and brachial arteries (Figure 3). In males, the average length in right antimere was $5.167 \pm 0.5815$ and in the left antimere was $5.245 \pm 0.6080$. In females, the average length in right antimere was $4.810 \pm 0.4688$ and left antimere was $4.995 \pm 0.5551 \mathrm{~cm}$.

6. Median nerve: found deriving from the ventral rami of C7, C8 and T1 (92.5\%), while in $7.5 \%$ of the animals it received no contribution from $\mathrm{T} 2$. This nerve with the musculocutaneous nerve formed a loop in which the axillary artery was suspended. This nerve ran in a caudolateral location relative to the brachial artery, where it received a communicating branch from the musculocutaneus nerve (Figure 3). The median nerve then continued distally to the medial elbow (Figure 4A and B). In males, the average length in right antimere was $14.29 \pm 1.828 \mathrm{~cm}$ and in the left antimere was $14.34 \pm 1.905 \mathrm{~cm}$. In females, the average length in right antimere was $13.52 \pm 1.097 \mathrm{~cm}$ and in left antimere antimere was $13.83 \pm 1.411 \mathrm{~cm}$.

7. Ulnar nerve: its fibers derived entirely from ventral branches of $\mathrm{C} 7, \mathrm{C} 8$ and $\mathrm{T} 1(92.5 \%)$ and in $7.5 \%$ of the animals it received no contribution from $\mathrm{T} 2$. This nerve was observed caudal to the median nerve. It descended together with the median nerve and was accompanied by the brachial vein. In the distal half of the humerus, the ulnaris nerve was located in a more caudal position and followed the margin of the medial epicondyle of the humerus (Figures 4A and B). In males, the average length in right antimere was $8.484 \pm 0.9721$ and in left antimere $8.380 \pm 1.777$. In females, the average length in right antimere was $7.704 \pm 0.6524$ and left antimere was $7.905 \pm 0.8782$.

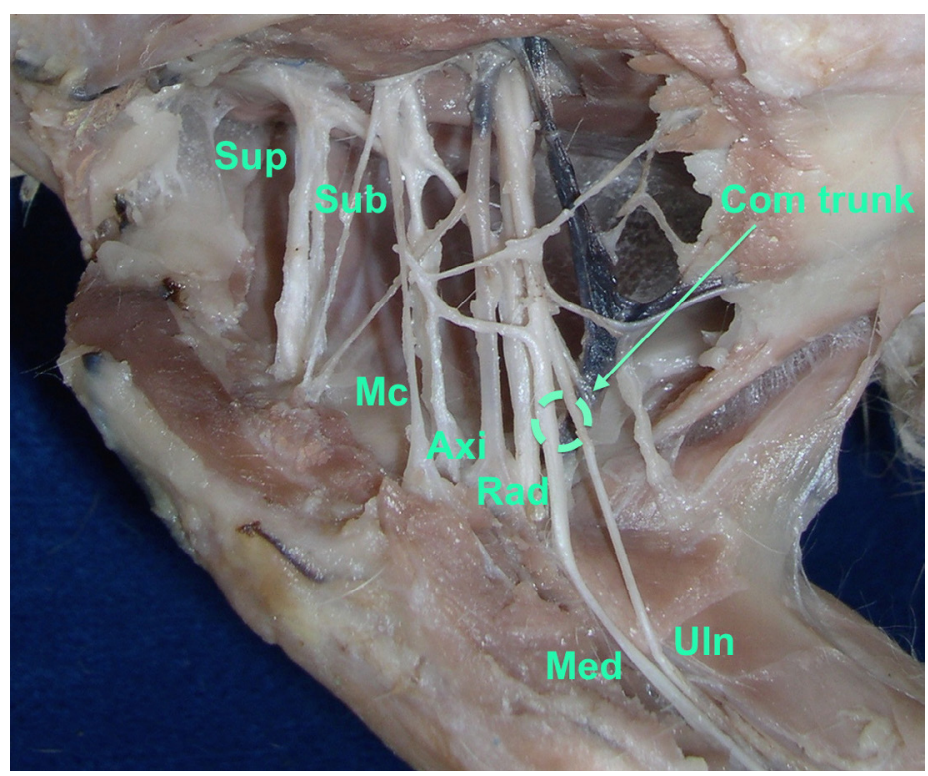

FIGURE 2 - Dissection appearance of the components of the brachial plexus identified from cranial to caudal as follows: suprascapular nerve (Sup), subscapular nerve (Sub), axillary nerve (Axi), musculocutaneus nerve (Mc), radial nerve (Rad) and the common trunk (Com trunk) of the median (Med) and ulnar nerve (ul).

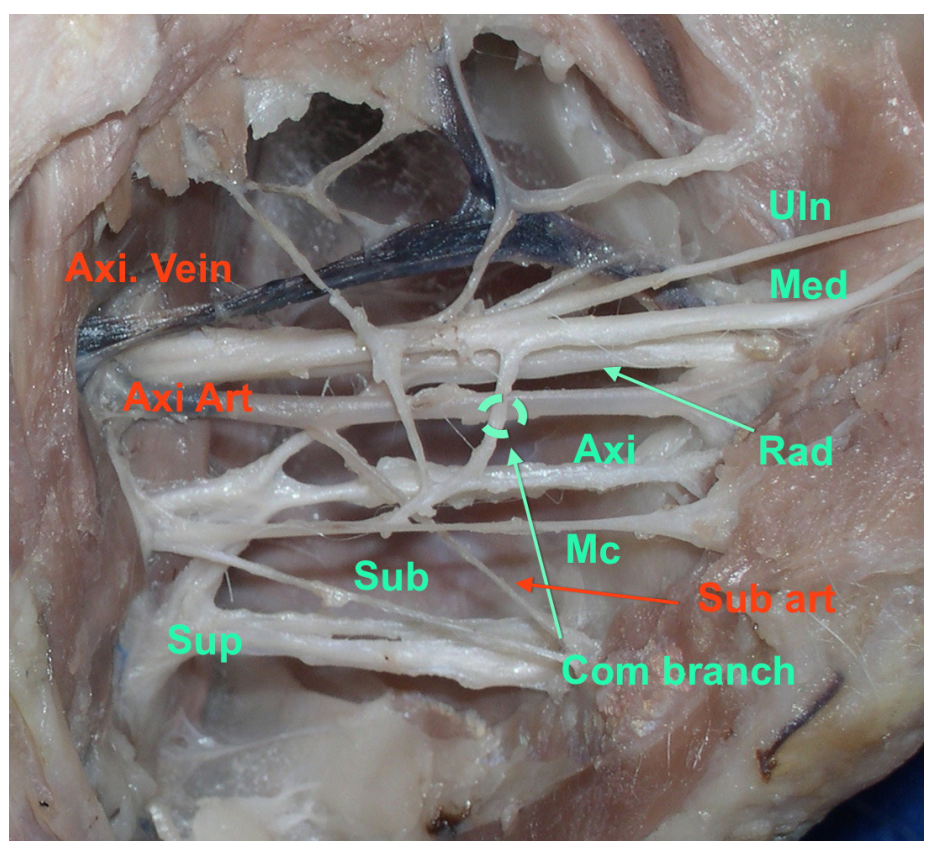

FIGURE 3 - Dissection appearance of the radial nerve (rad), which originates from the common trunk that contributes to the formation of the median and ulnar nerve. The median nerve (Med), which receives a communicating branch of the musculocutaneous nerve (Mc) form a handle (axillary handle) in which. They are also displayed in this photo the suprascapular nerve (Sup), subscapularis (Sub), axillary (Axi), median (Med) and ulnar (Uln). Axillary vein (Axi. Vein), Axillary artery (Axi Art) and Subscapular artery (Sub Art). 
The origins of the nerves and common spinal nerve origin of brachial plexus and the main peripheral nerves of the rabbit thoracic limb and their respective innervated muscles are described in Table 2.

TABLE 2 - Origins of the nerves, which comprise the rabbits brachial plexus.

\begin{tabular}{cccc}
\hline Nerves & Origin & $\begin{array}{c}\text { Absolut } \\
\text { Frequency }\end{array}$ & $\begin{array}{c}\text { Simple } \\
\text { Percentage } \\
\text { Frequency }\end{array}$ \\
\hline Suprascapular & C4- C5 & 2 & 1.25 \\
& C5 & 72 & 90 \\
Subscapular & C5-C6 & 6 & 9.75 \\
Axillary & C6-C6 & 80 & 100 \\
Musculocutaneus & C7-C8 & 72 & 100 \\
& C8-T1 & 8 & 90 \\
Radial & C8-T1 & 74 & 10 \\
& C8-T1-T2 & 6 & 92.5 \\
Median & C7-C8-T1 & 74 & 7.5 \\
& C7-C8-T1-T2 & 6 & 92.5 \\
Ulnar & C7-C8-T1 & 74 & 7.5 \\
& C7-C8-T1-T2 & 6 & 7.5 \\
\hline
\end{tabular}

TABLE 3 - Common spinal nerve origin of brachial plexus and the main peripheral nerves of the rabbit thoracic limb and respective innervated muscles.

\begin{tabular}{ccc}
\hline Peripheral Nerve & $\begin{array}{c}\text { Spinal Nerve } \\
\text { Origin }\end{array}$ & Innerveted Muscles \\
\hline Suprascapular & C5, filament C6 & Suprascapular \\
and C4* & C5 and C6 & Subscapular \\
Subscapular & Biceps brachii; \\
Axillary & C7 & brachiallis; superficial \\
Radial & C8, branches & pectorales muscle \\
Median & C7 and T1 & Teres major; \\
Ulnar & C8, T1 and T2* & subscapularis; \\
& C8, T1 and T2* & deltoideus; teres minor \\
& & Triceps brachii; \\
& & coracobrachialis; \\
& & extensor muscles \\
& & Pronator and flexor \\
& & muscles forearm \\
& & (exception carpi ulnaris) \\
& & Flexor muscles \\
& & forearm (exception \\
& & flexor carpi \\
& & radialis and deep \\
& & digital flexor-radial \\
& & head \\
& &
\end{tabular}

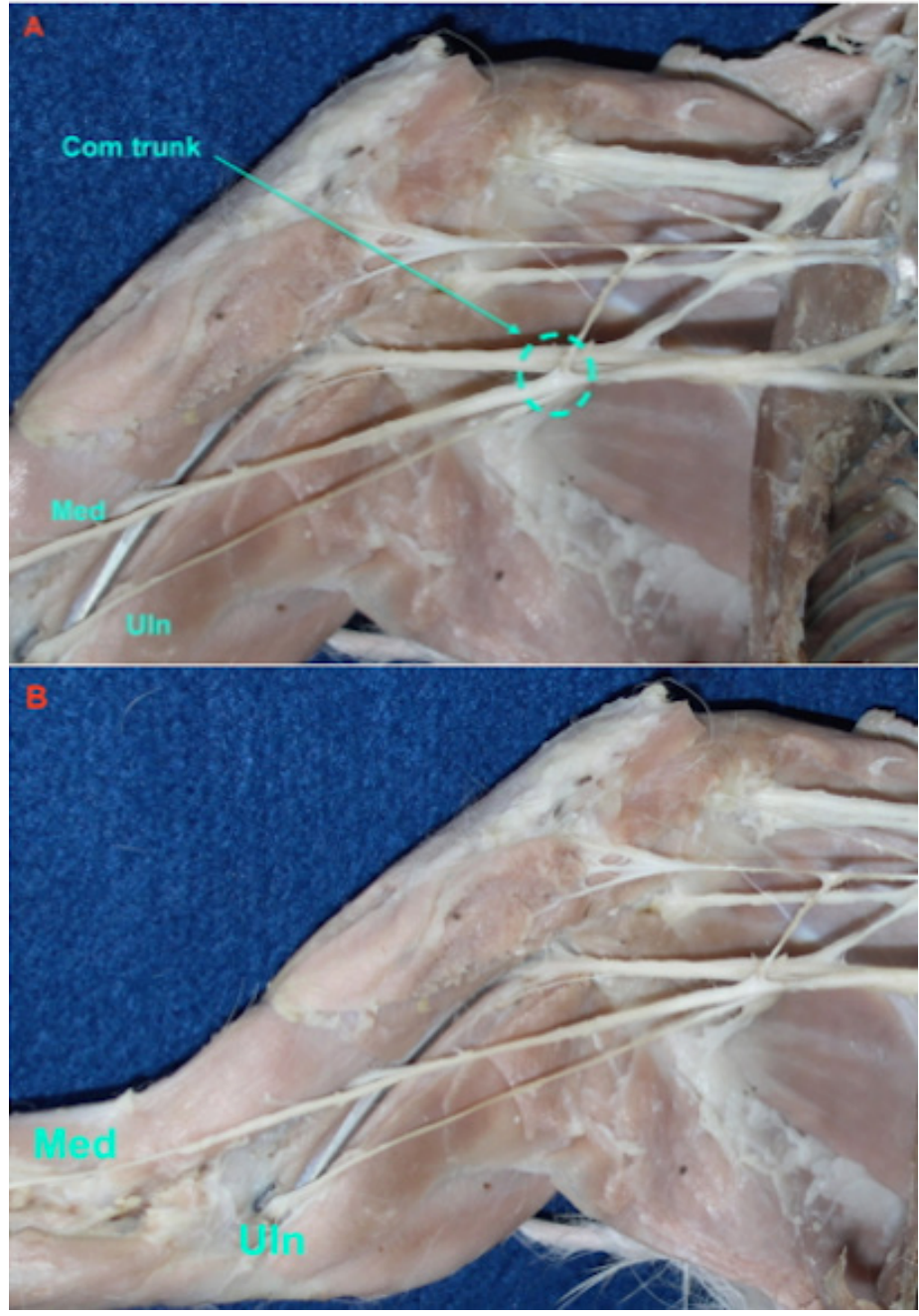

FIGURE 4 - (A) Picture of the median nerve (Med), ulnar nerve (Uln) and their common trunk (Com Trunk); (B) The ulnar nerve descended together with the median nerve. In the distal half of the humerus, the ulnaris nerve was located in a more caudal position and followed the margin of the medial epicondyle of the humerus.

\section{Ultrasonographic study}

A transverse image of the brachial plexus was obtained using the axillary approach by positioning the transducer in a parasagittal plane between the sternum and shoulder (Figure 5A), with the ultrasound beam directed craniodorsally. The brachial plexus appeared as an agglomerate of small, round hypoechoic structures surrounded by a thin hyperechoic ring. The nerve roots of C5, C6 and C7 were located cranial to the axillaris artery, while the nerve roots of $\mathrm{C} 8$ and $\mathrm{T} 1$ were identified lateral to the axillaris artery and closely related to the axillaris vein (Figure 5B). 


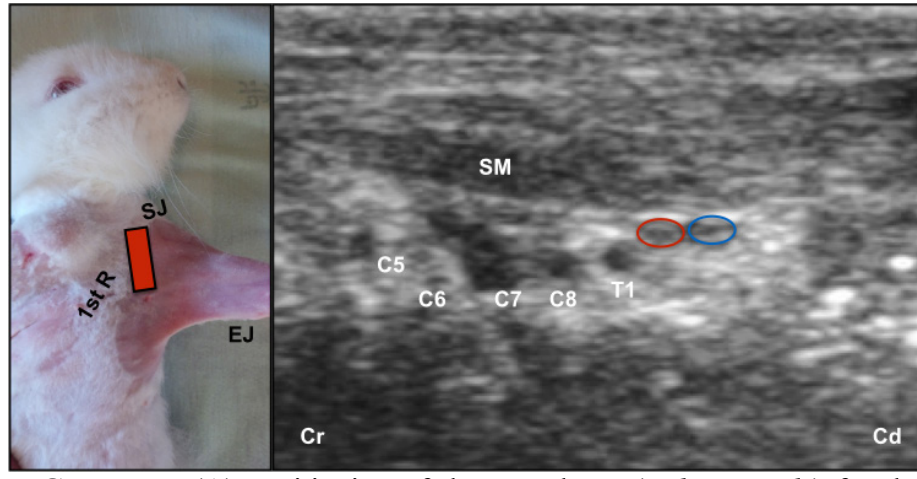

FIGURE 5 - (A) Positioning of the transducer (red rectangle) for the axillary approach. Anatomic landmarks are outlined by black dots. (B) Transverse ultrasound corresponding to the sonographic image of the roots of the brachial plexus $(\mathrm{C} 5, \mathrm{C} 6, \mathrm{C} 7, \mathrm{C} 8, \mathrm{~T} 1)$ at this level. Subscapularis vein (blue outline); Axillaris artery (red outline); SJ: Shoulder joint; EJ: Elbow joint; SM: Scalene muscle; First R: First rib; Cr: cranial; Cd: caudal.

Using the proximal and middle humeral approaches and positioning the transducer in a transverse plane on the medial aspect of the humerus, four oval-to-round hypoechogenic structures with a hyperechogenic ring were visualized caudal to the biceps brachii muscle. These structures were identified, from cranial to caudal, as brachialis artery, medianus nerve, and ulnaris nerve based on comparison of ultrasonographic images with the anatomic sections.

Transverse images of the medianus nerve and ulnaris nerve were obtained at the medial aspect of distal humerus approach. The brachialis artery was situated between both nerves. The medianus nerve was positioned cranial to the brachialis artery and caudal to the biceps brachii muscle. The medianus nerve appeared to be smaller in size than the ulnaris nerve. On the lateral aspect of the distal humerus, the superficial branch of the radialis nerve was seen caudal to the humerus and medial to the lateral head of the triceps brachii muscle.

In the ultrasound-guided brachial plexus block study, the nerve roots, neurostimulation needle and local anesthetic solution were easily spotted in eight rabbits used in this study (Figure 6). The amount of time and the minimum volume required to perform the technique was $4.3 \pm 2.3 \mathrm{~min}$ and $0.8 \pm 0.3 \mathrm{ml}$, respectively. We observed sensitivity and motor block in all of the rabbits.

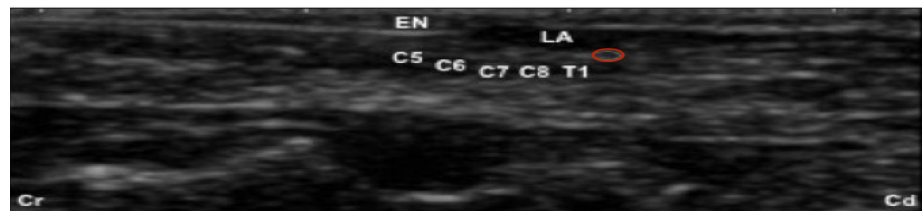

FIGURE 6 - Injection of lidocaine around the ventral roots of brachial plexus. Image of the anesthetic solution (hypoechogenic fluid) surrounding the roots of the brachial plexus $(\mathrm{C} 5, \mathrm{C} 6, \mathrm{C} 7, \mathrm{C} 8, \mathrm{~T} 1$ - hyperechoic structures in straight relation to axillary vascular structures). At this level. Axillaris artery (red outline); EN: electrostimulation needle; LA: local anesthetic; Cr: cranial; $\mathrm{Cd}$ : caudal.

\section{Discussion}

Experimental studies of the brachial plexus have been performed in rats, dogs, cats and other species. Furthermore, rabbits are considered suitable experimental models because of anatomical similarity of their brachial plexus with humans and pets. These studies focused on the macroscopic anatomy without morphometric analysis of brachial plexus and long branches of peripheral nerves.

In order to optimize the use of the domestic rabbit as an experimental model, the first phase of this research aimed to explain in detail the morphology and morphometry of the brachial plexus. It is noteworthy that important anatomical variations must be taken into account in this experimental model, such as the presence of nerve root of the fourth cervical spinal nerve and second thoracic spinal nerve, as evidenced in a small number of individuals in our study. The failure to check for these possible anatomic variations can lead to failure of blocking techniques and lead to invalidation of the research and greater animal suffering.

No veterinary anatomy treatise mentions the participation of $\mathrm{C} 4$ in the formation of the brachial plexus in domestic animals. In our study, the participation of $\mathrm{C} 4$ in one male rabbit was examined in detail to rule out any type of human error in interpretation. The participation of $\mathrm{C} 4$ in the formation of the brachial plexus can be explained by the more cephalic position of the forelimbs, so we can state that changes in the origin of plexus are due to variations in the insertion position of the forelimbs relative to the neuroaxis.

We observed participation of $\mathrm{C} 5$ in $100 \%$ of the animals. These findings are in accordance with a recent study ${ }^{10}$ describing in detail the anatomy of the brachial plexus in 18 rabbits.

Among the branches that always participated in the formation the brachial plexus in rabbits, the ventral branch of $\mathrm{C} 7$ was the largest root, which always configured a caliber connection with from $\mathrm{C} 8$ root, forming a trunk with $\mathrm{T} 1$ contribution, which derived nerves for the muscles of the caudomedial members and thoracic wall side of the chest. The ventral branches $\mathrm{C} 8$ and $\mathrm{T} 1$ are connected to the sympathetic trunk by means of a thin branch gray communicating branch, which provides the nervous system fibers.

The engagement of the second branch of the ventral spinal thoracic nerve was observed in $7.5 \%$ of the animals, and this participation occurred through a small connection with $\mathrm{T} 1$, but most of the time the $\mathrm{T} 2$ root forms the intercostal nerve, which runs through the internal and external intercostal muscles between the second and third ribs.

We observed three combination types of the brachial plexus ventral branches: type I (C5, C6, C7, C8 and T1 - 92.5\%), 
type II (C5, C6, C7, C8, T1 and T2 - 5.0\%) and type III (C4, C5, C6, C7, C8 and T1 - 2.5\%). The plexus type II and III are not mentioned in the literature on domestic species. Therefore, it is necessary for researchers using domestic rabbit models not to disregard the possibility of participation of the fourth cervical nerve and second thoracic nerve roots, as noted in our study.

In humans, the origin and location of the brachial plexus is similar as the rabbit. In both species it is located lateral to the cervical region of the spine and usually gives up the nerve segments C5 to T1. However, it is noteworthy that in humans the brachial plexus extends below and laterally, after the clavicle, to penetrate in the axilla, which is not observed in rabbits. Furthermore, the organization of brachial plexus branches in humans are joined to form the upper trunk (C5 and C6), medium (C7) and lower (C8 and $\mathrm{T} 1$ ), following the axillary artery under pectoralis major muscle ${ }^{11}$, and in the rabbit, this anatomical organization takes on a different arrangement, especially regarding the positioning of the axillary artery. Thus, it is apparent that there are anatomical differences among species, however, the anatomical similarities between species allows the anesthesiologist training in this experimental model.

In the second phase of this study, the brachial plexus was best visualized using the axillary approach, while the major nerves of the thoracic limb were best visualized using the humeral approach. The ultrasound approaches tested in this study were similar a study performed in cats ${ }^{2}$. We observed that the brachial plexus and its major nerves appeared as oval structures with hypoechoic shape surrounded by a hyperechoic ring in the transverse plane. These hyperechoic rings most likely represented the epineurium, whereas the hypoechoic area likely represented the neuronal fascicles and perineurium. These findings show the great importance of using ultrasound to prevent inadvertent injection in the intraneural pathway. Viewing this hyperechoic sheath allows great precision in the administration of local anesthetics.

The appearance os the major nerves was also similar to previous descriptions of peripheral nerves reported in cats ${ }^{2,12}$ and $\operatorname{dog} s^{5,13,14}$.

Using the axillary approach, the $\mathrm{C} 5, \mathrm{C} 6, \mathrm{C} 7, \mathrm{C} 8$ and $\mathrm{T} 1$ nerve roots of the brachial plexus, as well as the axillary artery and vein, appeared as an agglomerate of round hypoechoic structures. Identification of individual structures was possible mainly by comparing our anatomic results with those of other studies performed with different species ${ }^{2,6}$. In our study, we observed that the roots of the brachial plexus ( $\mathrm{C} 5, \mathrm{C} 6, \mathrm{C} 7, \mathrm{C} 8$ and $\mathrm{T} 1)$ are displayed in the axillary sonoanatomy, however, in humans, the terminals nerves (median, ulnar and radial) can be viewed in this same point. Therefore, this experimental model assumes an important role for appropriate positioning and alignment of the needle and the dispersion of the local anesthetic and not a reliable model for axillary sonoanatomy in humans.

Using the medial humeral approach, the radialis, medianus, and ulnaris nerves were readily identified in the proximal and mid-humerus areas. The musculocutaneous nerve was not clearly visualized, since it was thin and located close to the biceps brachialis muscle. In all rabbits, the ulnaris nerve was consistently the largest nerve structure in this area. The same finding has been reported in dogs and cats ${ }^{2,6}$. In this approach, recently some researchers have been studying the ultrasound guided mid-humeral block of the radial, ulnar, median and musculocutaneous nerves (RUMM block) in dogs with success in orthopedic surgery ${ }^{15}$.

The radialis nerve was observed as a cluster of very small nerve components in both the anatomic and ultrasound studies of our rabbits. The superficial branch of the radialis nerve was easily seen on the lateral aspect of the distal cranial humerus.

Adequate positioning of the rabbits was essential for US evaluation of the different branches of the brachial plexus. In the in vivo ultrasonographic study, sedation was useful for retracting the shoulder and keeping the contralateral limb abducted and pulled caudally. In all cases, scans were carried out using a simple linear frequency transducer. The main limitation of this study was that due to the small size of the animals, the area to be scanned was small in comparison to the size of the transducer. As a result, longitudinal images of the nerves could not be obtained in any rabbit.

To perform locoregional ultrasound-guided brachial plexus block, a key requirement for success is to ensure optimum distribution of local anesthetic in close proximity to the nerve roots and/or major nerves ${ }^{16,17}$. This goal can be more effectively achieved by using sonographic visualization rather than being performed blindly. Furthermore, a recent study performed with rabbits showed that this combination of techniques enables successful nerve block in a short time ${ }^{8}$. In our study, we reproduce the technique with ease successfully in all the animals tested.

An advantage of the ultrasound-guided block is to reduce the required volume of local anesthetic and minimize accidental vascular and intraneural puncture ${ }^{17,18}$. We observed with accuracy the deposition of the solution in the $\mathrm{C} 5, \mathrm{C} 6, \mathrm{C} 7, \mathrm{C} 8$ and $\mathrm{T} 1$ nerve roots. Therefore, one can administer the appropriate minimum quantity to soak these nerve structures. In the above study ${ }^{8}$, the researchers mentioned a reduction of 12.5 to $25 \%$ of the volume of anesthetic in some animals without reducing the duration of 
sensory and motor blockade. Furthermore, reducing the volume of the local anesthetic makes the procedure safer regarding poisoning, which is common in animals with small body weight.

In summary, ultrasound-guided axillary brachial plexus block is not a difficult procedure in rabbits and in humans. Nevertheless, without detailed knowledge of the anatomy of the brachial plexus and the most common anatomical variants, the use of ultrasonography does not always facilitate efficient anesthesia ${ }^{4}$ Thus, due to the advantages and similarities aforementioned, the rabbit can serve as an experimental model and reduce the learning curve of the anesthesiologist professional.

\section{Conclusions}

This study reports an update of macroscopic and sonographic anatomy of the brachial plexus of the domestic rabbit, showing some morphological variations among animals, however with low prevalence. Moreover, from anatomical sonographic landmarks previously described, we showed complete reproducibility of the axillary ultrasound-guided brachial plexus block with a simple resolution device and small doses of anesthetics required.

\section{References}

1. Kehlet H, Dahl J. The "value" of multimodal or "balanced analgesia" in postoperative pain treatment. Anesth Analg. 1993;(77):1048-56. PMID: 8105724

2. Anson A, Laredo FG, Gil F, Soler M, Belda E, Ayala MD, Agut A. Comparison of two techniques for ultrasound-guides axillary brachial plexus blockade in cats. J Feline Med Surg. 2015 Jun;17(6):476-85. doi: 10.1177/1098612X14548785.

3. Mencalha R, Fernandes N, Sousa CA, Abidu-Figueiredo, M. A cadaveric study to determine the minimum volume of methylene blue to completely color the nerves of brachial plexus in cats. An update in forelimb and shoulder surgeries. Acta Cir Bras. 2014 Jun;29(6):382-8. PMID: 24919047.

4. Nowakowski P, Bierylo A. Ultrasound guided axillary brachial plexus block. Part 1 - Basic sonoanatomy. Anaesthesiol Intensive Ther. 2015;47(4):409-16. doi: 10.5603/AIT.2015.0052.

5. Guilherme S, Benigni L. Ultrasonographic anatomy of the brachial plexus and major nerves of the canine thoracic limb. Vet Radiol Ultrasound. 2008 Nov-Dec;49(6):577-83. PMID: 19051650.

6. Reichert P, Kielbowicx Z, Giel P, Pula B, Kuryszko J, Gosk J, Bochenska A. The rabbit brachial plexus as a model for nerve repair surgery - histomorphometric analysis. Anat Rec. 2015 Feb;298 (2):444-54. PMID: 25284580.

7. Anson A, Gil F, Laredo F, Soler M, Belda E, Ayala M, Agut A. Comparative ultrasound anatomy of the feline brachial plexus and major nerves of the thoracic limb. Vet Radiol Ultrasound. 2013 MarApr;54(2):185-93. doi: 10.1111/vru.12012.

8. Fonseca C, Server A, Esteves M, Barastegui D, Rosal M, Fontecha C, Soldado F. An-ultrasound technique for axillary brachial plexus nerve block in rabbits. Lab Anim (NY). 2015 May;44(5):179-84. doi: 10.1038/laban.732.
9. Wakoff T, Mencalha R, Souza N, Santos-Sousa C, Desterro M, Scherer P. Bupivacaína $0,25 \%$ versus ropivacaína $0,25 \%$ no bloqueio do plexo braquial em cães da raça beagle. Sem Cienc Agra. 2013;34(3):1259-72. doi: 10.5433/1679-0359.2013.

10. Reichert P, Rutowski R, Kielbowicz Z, Kuryszki J, Kielbowicz M, Michalak L, Bochenska A. The rabbit brachial plexus as an experimental model - anatomy and surgical approach. Pol J Vet Sci. 2014;17(2):339-45. PMID: 24988861.

11. Saeed M, Rufai, A. A median and musculocutaneos nerves: variant formation and distribution. Clin Anat. 2003 Sep;16(5):453-7. PMID: 12903070 .

12. Haro P, Gil F, Laredo F, Ayala MD, Elda E, Soler M, Agut A. Ultrasonographic study of the feline sciatic nerve. J Feline Med Surg. 2011 Apr;13(4):259-65. PMID: 21276740.

13. Echeverry DF, Gil F, Laredo F, Ayala MD, Elda E, Soler M, Agut A. Ultrasound-guided block of the sciatic and femoral nerves in dogs: a descriptive study. Vet J. 2010 Nov;186(2):210-5. PMID: 19758827.

14. Portela DA, Raschi A, Otero PA. Ultrasound guided mid-humeral block of the radial, ulnar, median and musculocutaneous (RUMM block) nerves in a dog with traumatic exposed metacarpal luxation. Vet Anaesth Analg. 2013 Sep;40(5):552-4. doi: 10.1111/vaa.12046.

15. Campoy L, Bezuidenhout AJ, Gleed RD, Martin-Flores M, Raw RM, Santare CL, Jay AR, Wang, AL. Ultrasound-guided approach for axillary brachial plexus, femoral nerve, and sciatic nerve blocks in dogs. Vet Anaesth Analg. 2010 Mar;37(2):144-53. doi: 10.1111/j.1467-2995.2009.00518.x.

16. Rioja E, Sinclair M, Chalmers H, Foster RA, Monteith G. Comparison of three techniques for paravertebral brachial plexus blockade in dogs. Vet Anaesth Analg. 2012 Mar;39(2):190-200. doi: 10.1111/j.1467-2995.2011.00677.x.

17. Jeng $C$, Rosenblatt $M$. Intraneural injections and regional anesthesia: the known and the unknown. Minerva Anesthesiol. 2011 Jan;77:548. PMID: 21273966.

18. Steinfeldt T, Werner T, Nimphius W, Wiesmann T, Kill C, Muller $\mathrm{H}$, Wulf $\mathrm{H}$, Graf J. Histological analysis after peripheral nerve puncture with pencil-point or tuohy needletip. Anesth Analg. 2011 Feb;112(2):465-70. doi: 10.1213/ANE.0b013e318202cb9c.

\section{Correspondence:}

Rodrigo Mencalha

Faculdade de Medicina Veterinária de Valença

Centro de Ensino Superior de Valença

Avenida Sargento Vitor Hugo, 161

27.600-000 Valença-RJ Brasil

direcaofmvv@gmail.com

Received: Dec 09, 2015

Review: Feb 10, 2016

Accepted: Mar 11, 2016

Conflict of interest: none

Financial sources: FAPERJ and CNPq

${ }^{1}$ Research performed at Anatomy Laboratory, Universidade Federal Rural do Rio de Janeiro, Seropédica-RJ, and the Veterinary Polyclinic of Small Animals, Centro de Ensino Superior de Valença (CESVA), Valença-RJ, Brazil. 